\title{
Potential Therapeutic Use of Neurosteroids for Hypertension
}

\author{
Geoffrey A. Head*, Kristy L. Jackson and Cindy Gueguen \\ Neuropharmacology Laboratory, Baker Heart and Diabetes Institute, Melbourne, VIC, Australia
}

The sympathetic nervous system (SNS) contribution to long-term setting of blood pressure (BP) and hence hypertension has been a continuing controversy over many decades. However, the contribution of increased sympathetic vasomotor tone to the heart, kidney, and blood vessels has been suggested as a major influence on the development of high BP which affects $30-40 \%$ of the population. This is relevant to hypertension associated with chronic stress, being overweight or obese as well to chronic kidney disease. Treatments that have attempted to block the peripheral aspects of the SNS contribution have included surgery to cut the sympathetic nerves as well as agents to block $\alpha$ - and $\beta$-adrenoceptors.

\section{OPEN ACCESS}

Edited by:

Maarten Koeners,

University of Bristol,

United Kingdom

Reviewed by: Mohammed H. Abdulla, University College Cork, Ireland

Zhanjun Jia,

Nanjing Medical University,

China

${ }^{*}$ Correspondence: Geoffrey A. Head geoff.head@baker.edu.au

Specialty section:

This article was submitted to Renal and Epithelial Physiology, a section of the journal

Frontiers in Physiology

Received: 07 October 2019 Accepted: 18 November 2019 Published: 12 December 2019

Citation:

Head GA, Jackson KL and Gueguen C (2019) Potential

Therapeutic Use of Neurosteroids for Hypertension.

Front. Physiol. 10:1477. doi: 10.3389/fphys.2019.01477
Other treatments, such as centrally acting drugs like clonidine, rilmenidine, or moxonidine, activate receptors within the ventrolateral medulla to reduce the vasomotor tone overall but have side effects that limit their use. None of these treatments target the cause of the enhanced sympathetic tone. Recently we have identified an antihypertensive action of the neurosteroid allopregnanolone in a mouse model of neurogenic hypertension. Allopregnanolone is known to facilitate high-affinity extra-synaptic $\gamma$-aminobutyric acid $A$ receptors $\left(G A B A_{A} R\right)$ through allosteric modulation and transcriptional upregulation. The antihypertensive effect was specific for increased expression of $\delta$ subunits in the amygdala and hypothalamus. This focused review examines the possibility that neurosteroids may be a novel therapeutic approach to address the neurogenic contribution to hypertension. We discuss the causes and prevalence of neurogenic hypertension, current therapeutic approaches, and the applicability of using neurosteroids as antihypertensive therapy.

Keywords: neurogenic hypertension, allopregnanolone, $\gamma$-aminobutyric acid receptor A, amygdala, hypothalamus, Schlager mice, sympathetic nervous system

\section{INTRODUCTION}

Hypertension is a major risk factor for cardiovascular events particularly stroke and myocardial infarction. A recent population cohort study from Australia, using ambulatory blood pressure (BP) monitoring, found that the prevalence of hypertension was a staggering $43 \%$ with only $25 \%$ taking antihypertensive medication of which a third were not reaching target BP (Head et al., 2019). A total of $21 \%$ had masked hypertension, which occurs when BP measurements made in the clinical setting are within the normal range but BP is above threshold for hypertension during the stresses and strains of normal daily life (Head et al., 2019). While the cause of hypertension is still highly debated, there are a number of factors such as obesity, insulin resistance, high alcohol intake, low potassium intake, chronic inflammation, salt, stress, 
and lifestyle which have been suggested as mechanisms (Carretero and Oparil, 2000). A large case-control study involving nearly 25,000 participants from 52 countries examined factors associated with a first myocardial infarction and found a much higher prevalence of psychosocial stress among cases than controls. The stress was assessed by questions about work stress, home stress, financial stress, and major life events which contributed to $33 \%$ of the total risk (Rosengren et al., 2004). The mediators of the risk were not determined but clearly activation of the sympathetic nervous system (SNS) is a major influence (Seravalle and Grassi, 2016). The authors contend that visceral obesity, reflex impairment, metabolic factors (insulin and leptin) as well as the renin-angiotensin system (RAS) and oxidative stress all interact to increase the activity of the SNS. This activation causes hypertension, inflammation, organ damage, and activates clotting mechanisms to increase cardiovascular risk (Seravalle and Grassi, 2016). The focus of the current mini review is to explore the causes and prevalence of neurogenic hypertension, current therapeutic approaches, and the applicability of using neurosteroids that modulate specific $\mathrm{GABA}_{\mathrm{A}} \mathrm{R}$ activity as a novel antihypertensive therapy.

\section{CONTRIBUTION OF THE SYMPATHETIC NERVOUS SYSTEM TO HUMAN HYPERTENSION}

There is a growing recognition of the importance of the SNS as an underlying cause of hypertension but difficulty in assessing sympathetic activity has been a major limitation. A review by Fisher and Paton stated that "A neurogenic component to primary hypertension is now well established. Along with raised vasomotor tone and increased cardiac output, the chronic activation of the SNS in hypertension has a diverse range of pathophysiological consequences independent of any increase in BP" (Fisher and Paton, 2012). Techniques for studying the human SNS have included electrical recording of skeletal muscle postganglionic sympathetic nerve fibers (clinical microneurography) and isotope dilution measurement of norepinephrine release from sympathetic nerves to plasma (norepinephrine spillover). These have been used over the past three decades in patients with essential hypertension and there is consensus that there is activated sympathetic outflow to the skeletal muscle vasculature, heart, and kidneys in $40-65 \%$ of patients but not to the gut, liver, or adrenals (Esler et al., 1988a, 2006; Anderson et al., 1989; Yamada et al., 1989; Rumantir et al., 1999). In obesity-related hypertension, cardiac noradrenaline spillover is reduced (Esler et al., 2006). Of all the regional beds, the sympathetic activity to the kidney appears to be the most important for influencing or initiating hypertension (Esler et al., 2010). The effects of the renal sympathetic nerves on renal tubular reabsorption of sodium,

Abbreviations: SNS, Sympathetic nervous system; $\mathrm{GABA}_{\mathrm{A}} \mathrm{R}, \boldsymbol{\gamma}$-aminobutyric acid A receptors; CRF, Corticotrophin-releasing factor; BP, Blood pressure; PVN, Paraventricular nucleus; RAS, Renin-angiotensin system; SHR, Spontaneously hypertensive rats; ACTH, Adrenocorticotrophic hormone. renin release, and glomerular filtration rate are now seen to provide hypertension-producing mechanisms but without affecting renal hemodynamics (DiBona and Kopp, 1995; DiBona and Esler, 2010). Younger people with mild essential hypertension commonly have high renin hypertension due to elevated renal sympathetic activity which results in greater secretion of renin (Rumantir et al., 1999). Esler suggested that "Renin-angiotensin inhibitors work well in these patients, in part because they are countering neurally mediated RAS activation" (Esler et al., 2010).

\section{WHAT CAUSES NEUROGENIC HYPERTENSION}

Chronic stress, which activates the renal and cardiac sympathetic outflows, has been suggested as a possible mechanism leading to neurogenic hypertension (Esler et al., 2008a,b). There is a well-recognized clinical comorbidity of a number of stress disorders with essential hypertension (Davies et al., 1999). This is exemplified in anxiety and panic disorder where, in the longer term, there is an association with the development of hypertension (Davies et al., 1999). Furthermore, stress increases the susceptibility of individuals to cardiovascular events (Bunker et al., 2003). A large multisite study investigating the correlation between psychosocial stress and myocardial infarction demonstrated that individuals who experienced chronic stress were an alarming 2-fold more likely to develop myocardial infarctions than controls (Rosengren et al., 2004). Further evidence that chronic stress is a risk factor for cardiovascular complications is demonstrated by the link between stress, SNS activity, and hypertension. SNS activity is shown to be positively correlated with BP in pre-hypertensive individuals (Esler et al., 1988b; Flaa et al., 2008). In addition to chronic stress, stress reactivity is proposed to be a risk factor for the future development of hypertension. One of the most well-known studies involved a long-term follow-up of nuns living in a monastery in Italy who were compared with matched women in the local community (Timio et al., 2001). The surprising finding was that over 32 years, the level of systolic and diastolic BP remained constant in the nuns but was elevated substantially in the control women. The authors could find no other lifestyle factors such as salt intake, body weight, body mass index, cholesterol, parity, or alcohol that contributed to the difference except for the level of psychosocial factors (Timio et al., 2001). Matthews and colleagues demonstrated that normotensive individuals with a heightened pressor response to stress were four times more likely to develop hypertension than those with a lower pressor response (Matthews et al., 2004). Furthermore, BP reactivity to stress was shown to predict BP at a 5 year follow-up, with the magnitude of the reactivity predicting the magnitude of the upward drift (Carroll et al., 2003). Flaa and colleagues demonstrated that increased activity of the SNS in response to stress was also a predictor of the subsequent development of hypertension (Flaa et al., 2008). Additionally, chronic stress is associated with increased SNS activity and elevated BP in patients with stress disorders (Schnall et al., 1998). This is 
epitomized in subjects with white coat hypertension who only demonstrate hypertension during the anxiety experienced in a clinical setting. These patients have an exaggerated morning surge in BP and elevated day time BP compared with normotensive controls (Head et al., 2010) and are likely to go on to develop chronic hypertension (Kollias et al., 2014). Together, this provides further evidence that heightened SNS activation and subsequently BP reactivity in response to stress may contribute to the pathogenesis of hypertension.

\section{ANIMAL MODELS OF CHRONIC STRESS-INDUCED HYPERTENSION}

There have been a large number of studies that have attempted to investigate the association between chronic stress and hypertension. A review of 20 studies found that the ability to produce psychogenic hypertension in rodents was inconsistent, with 6 studies finding no effect (Nalivaiko, 2011). A range of stressful interventions including foot shock, airjet, restraint, crowding, and predator exposure were used with durations from a few weeks to several months. A positive effect was only recorded with studies using tail cuff or direct cannulation to measure BP (Nalivaiko, 2011) but not when radiotelemetry was used. A later review included 36 studies but came to the same conclusion that animal studies have failed to consistently find an elevation of BP following chronic stress (Crestani, 2016). A telemetry BP study from the same authors as the review and another independent study provided further evidence that a variable stress schedule for 10-14 consecutive days or 4 weeks of daily restraint stress does not affect chronic BP (Flak et al., 2011; Costa-Ferreira et al., 2016; Sikora et al., 2016; Goodson et al., 2017). One of the main differences between the evidence in humans and the lack of evidence in animal models is in most cases the short duration of the stress in the latter. Interestingly, in conscious rabbits, combining a high-cholesterol diet with daily variable stress for 2 or 4 months resulted in a marked stress-induced hypertension ( $\mathrm{Lu}$ et al., 2012). Regrettably, the stress alone paradigm was not included in the design and it is not clear whether the added impact of an atherosclerotic diet potentiated or was necessary to observe stress-induced hypertension.

Perhaps the best evidence for the impact of chronic stress on hypertension comes from specifically bred animals that over many generations have become an inbred model of neurogenic hypertension. The stress-sensitive hypertension rat developed by Markel in 1992 is an excellent and possibly unique development (Markel, 1992; Redina and Markel, 2018). In a recent review of the strain, Redina and Markel suggested that the existence of the model was "proof that a genetic predisposition to increased stress-reactivity causes hypertension" (Redina and Markel, 2018). Interestingly, the breeding program was not successful in selecting for an enhanced response to stress without increasing basal BP. The strain is associated with greater reactivity of the hypothalamic pituitary axis and increased expression of corticotrophin-releasing factor (CRF) in the hypothalamus both at rest and during stress (Markel et al., 2007).
The borderline hypertensive rat, a cross between spontaneously hypertensive rats (SHR) and normotensive Wistar Kyoto rats, was developed as a possible model for environmentally induced hypertension (Lawler et al., 1980). This strain gradually developed substantial sustained hypertension over several months from a moderate base when subjected to conflict, but mild restraint stress had no effect (Lawler et al., 1981). A later study used telemetry to measure BP and confirmed the earlier findings measured by tail cuff techniques, but did not find borderline hypertensive rats to be sensitive to chronic social stress. The protocol involved changing the housing of the male rats with three novel female rats every day for 4 weeks (Lemaire and Mormede, 1995). However, whether this strain represents a model of neurogenic hypertension remains to be determined.

The BP high (BPH/2) strain of mouse developed by Schlager in the 1970s (Schlager, 1974), which involved a cross breeding program with eight normotensive strains, were selected using tail cuff methodology which is known in itself to elevate BP. These mice have sustained hypertension from an early age (Herat et al., 2020) and when adult, the hypertension can be abolished by blocking the SNS, suggesting that these mice display neurogenic hypertension (Davern et al., 2009). One of the important aspects of their phenotype is that they show a marked exaggeration in $\mathrm{BP}$ response compared to normotensive controls when subjected to aversive stressors such as being swapped into a cage previously occupied by another male mouse or being restrained in a plexiglass container (Davern et al., 2010b). By contrast, these mice show the same percentage elevation in BP during a pleasurable non-aversive stimulus such as being given an almond (Davern et al., 2010b). This indicates that the exaggerated response to aversive stress was not simply a vascular amplification effect of the sustained hypertension. Interestingly, the $\mathrm{BPH} / 2$ mice in response to aversive stressors have marked elevation of neuronal activity in the amygdala and hypothalamus (Davern et al., 2010a).

\section{ROLE OF AMYGDALO-HYPOTHALAMIC PATHWAYS}

Stress responses involve integration of afferent information at the thalamic, cortical, and subcortical level and result in the release of neurotransmitters that potentiate autonomic and emotional responses via the hypothalamus and amygdala (Korner, 2007). Sensory and cognitive information is processed in the amygdala and the particular behavioral responses are mediated by the amygdalo-hypothalamic pathways and their downstream projections (LeDoux, 2003). Both the central and medial amygdalae mediate the activation of the hypothalamic-pituitary axis (Swanson and Petrovich, 1998). Specifically, neurons from these areas project directly and indirectly to the paraventricular nucleus (PVN) of the hypothalamus (Herman et al., 2003). CRF neurons are directly activated within the PVN by projections from the amygdala, causing the release of adrenocorticotrophic hormone (ACTH) 
from the anterior pituitary gland. Circulating ACTH acts within the adrenal cortex to potentiate the release of cortisol (Whitnall, 1993). Central injections of a CRF antagonist blocked the acute pressor response to cage switch stress in rats (Nakamori et al., 1993) but increased BP in unstressed animals (Nakamori et al., 1993). In both young and adult SHR, restraint stress has been observed to elevate mRNA of CRF and of the CRF type 1 receptor to a greater degree than in normotensive Wistar Kyoto rats (Imaki et al., 1998). This suggests there is enhanced activation of the hypothalamicpituitary axis following stress during both the development and maintenance of experimental hypertension. An important future direction would be to examine the chronic effect of the CRF antagonist given centrally on neurogenic hypertension. Untreated hypertensive patients also have greatly activated CRF-containing neurons in the hypothalamus (Goncharuk et al., 2002). The CRF counts in all but one of the hypertensive patients exceeded the $95 \%$ confidence intervals of the normotensive patients suggesting that this phenomenon is very widely applicable to human hypertension. CRF neurons in the hypothalamus are under tonic GABAergic inhibition. The link between GABA and chronic stress is well summarized by a recent review, although the emphasis was on neuropsychiatric disease (Jie et al., 2018). Thus, we contend that chronic stress may downregulate GABA inhibition of amygdala and hypothalamic pathways leading to hypertension. The duration, severity, and type of stress as well as the hormonal status of the individual may result in different degrees of impact on the SNS (Pickering, 1997). $\mathrm{GABA}_{\mathrm{A}} \mathrm{R}$ can be modulated by neurosteroids acting on receptors containing the $\delta$ subunit (Sarkar et al., 2011). Further, GABA supplements reduce BP by $\sim 10 \mathrm{mmHg}$ in hypertensive patients (Shimada et al., 2009), which is more than what is expected from monotherapy. Thus, there is growing evidence to suggest that a lack of GABAergic inhibition in the forebrain of humans makes a major contribution to the development of hypertension (Dampney et al., 2005). It would appear then that the neurogenic component of hypertension is commonly associated with CRF neuron activation in the hypothalamus in man, mouse, and rat.

\section{TREATMENT OPTIONS FOR NEUROGENIC HYPERTENSION}

At present, there are no specific treatments targeting neurogenic forms of hypertension that arise from an exaggerated response to stress. However, there are treatments and interventions that do target the SNS.

Beta blockers are effective antihypertensive agents but mainly affect cardiac sympathetic activity and reduce renin release. These drugs have been used for many decades and while safe are now only used as a second-line treatment option. They are only effective during the day when the subject is active. They have little effect on the early morning rise in BP, which is the time of greatest SNS activity (Raftery, 1993).
Centrally acting antihypertensive drugs such as clonidine, rilmenidine, or moxonidine do inhibit sympathetic activity by an action on imidazoline receptors and $\alpha_{2}$-adrenoceptors at the level of the rostro-ventrolateral medulla (Head et al., 1997). However, these drugs do not prevent the sympathetic response to stress in human hypertension (Esler et al., 2004) or in animal models of hypertension (Head and Burke, 2004) and are not first-line treatments presumably due to significant side effects and lack of long-term outcome studies.

Renal denervation is effective in a number of trials particularly in resistant hypertension (Weber et al., 2019) but it is not clear if the nerves will regrow and there is no effective way to determine who is suitable for renal denervation and whether the technique has actually been effective (Weber et al., 2019). Indeed, a major trial known as Simplicity 3 which was a sham-controlled study failed to show a difference between active and sham treatments, mainly because it became apparent that few subjects were effectively denervated (Laffin and Bakris, 2015; Burchell et al., 2016).

\section{NEUROSTEROID ALLOPREGNANOLONE TREATMENT FOR NEUROGENIC HYPERTENSION}

These options only effectively target the sympathetic outflow and not the cause or region of origin of the high SNS activity contributing to hypertension. We have found that the neurosteroid allopregnanolone is effective in reducing BP and the pressor response to stress in a mouse model of neurogenic hypertension (Stevenson et al., 2017). The BP lowering actions of allopregnanolone involve sympatho-inhibition via upregulation of $\mathrm{GABA}_{\mathrm{A}} \mathrm{R}$ that specifically contain $\delta$ subunits in the hypothalamus and amygdala (Stevenson et al., 2017). Evidence for a sympatho-inhibitory action came from the attenuation of the depressor response to the ganglion-blocking agent pentolinium, and also the inhibition of the pressor response to restraint and cage swap stress (Stevenson et al., 2017). It must be remembered that allopregnanolone did not abolish the hypertension but attenuated the difference between strains. The reduction of $\sim 10 \mathrm{mmHg}$ was very similar to that achieved by lesions of the medial amygdala in this strain (Jackson et al., 2014). Our hypothesis is that chronic stress may reduce the endogenous levels of allopregnanolone and lead to downregulation of $\mathrm{GABA}_{\mathrm{A}} \mathrm{R}$ containing $\delta$ subunits leading to activation of the SNS (Figure 1). The question is then why are $\mathrm{BPH} / 2 \mathrm{~J}$ mice chronically stressed and is there any evidence to suggest this? Indeed, $\mathrm{BPH} / 2 \mathrm{~J}$ hypertensive mice display activated CRF neurons in the hypothalamus that have been shown in human hypertension (see above). To our knowledge, this is the first study to explore the therapeutic potential of allopregnanolone in a model of hypertension. Clinically, there is a strong association of heightened activity of stress pathways with an exaggerated cardiovascular response to stress (Gianaros et al., 2008), which serves as a risk factor for the development of hypertension 


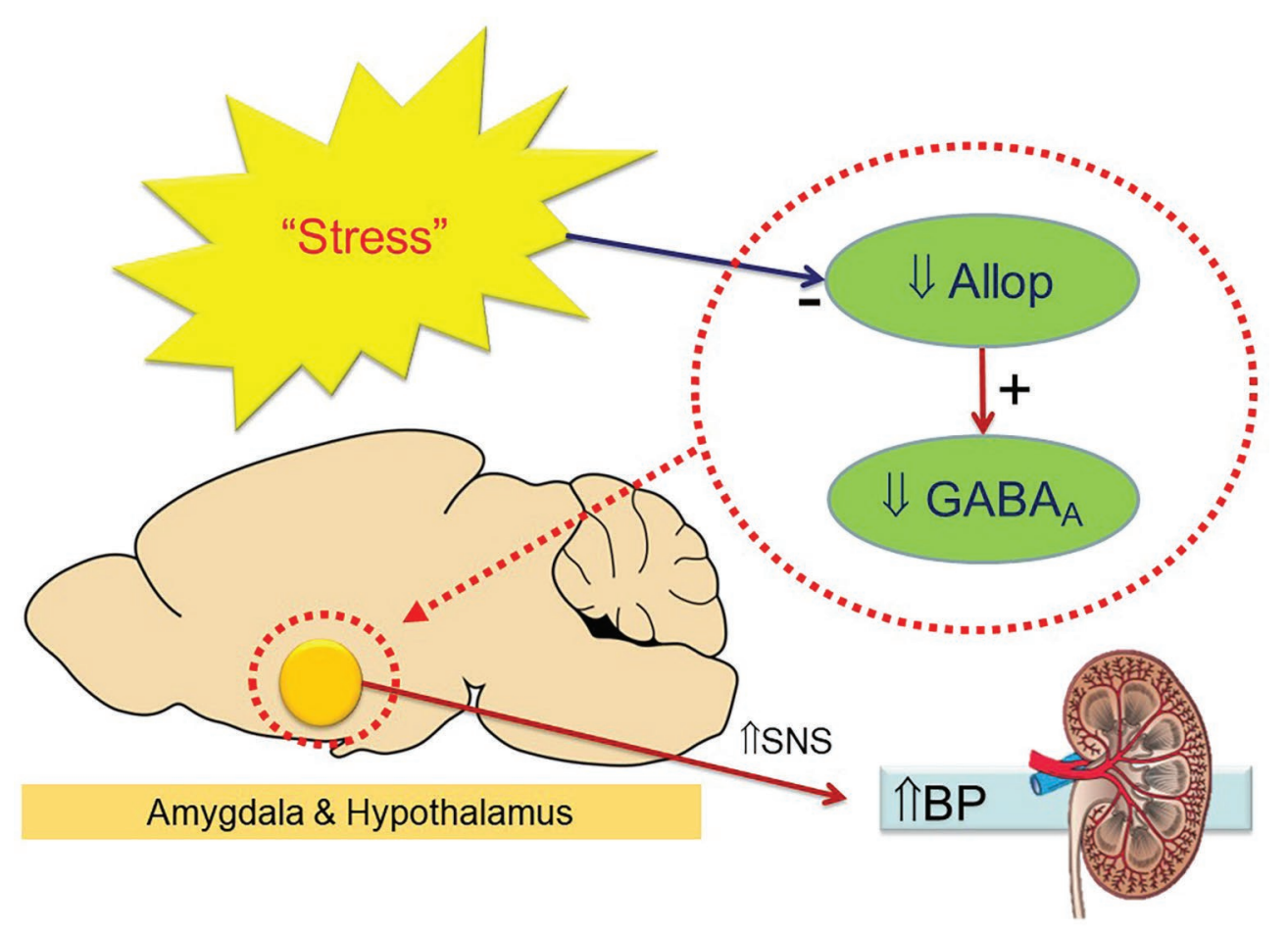

FIGURE 1 | Schema indicating the hypothesis that chronic stress reduces endogenous allopregnanolone (Allop) in the hypothalamus and amygdala leading to a reduced expression of $\mathrm{GABA}_{\mathrm{A}}$ receptors and an increase in sympathetic activity (to kidney and other organs) to elevate blood pressure. Treatment with neurosteroids reverses this process.

(Matthews et al., 2004). The attenuated pressor responses to stress following allopregnanolone were shown to closely correlate with changes in stress-induced neuronal activity of the hypothalamus. Thus, impaired GABAergic inhibition may be a common characteristic of neurogenic hypertension. This conclusion is further supported by the association of the selective reduction in $\mathrm{BP}$ and sympathetic vasomotor drive following allopregnanolone with enhanced expression of $\mathrm{GABA}_{\mathrm{A}}$ subunits that mediate tonic neuronal inhibition. Therefore, selectively modulating $\mathrm{GABA}_{\mathrm{A}} \mathrm{R}$ with neurosteroids such as allopregnanolone may offer a novel area of therapy to attenuate hyperactivity of neuronal pathways in neurogenic hypertension. Ganaxolone is a safe synthetic neurosteroid that upregulates the expression of specific $\mathrm{GABA}_{\mathrm{A}} \mathrm{R}$ in the forebrain and increases the level of tonic inhibition. Thus, treatment with ganaxolone may have significant beneficial effects in reducing the adverse impact of high levels of sympathetic nerve activity observed in hypertensive patients and offer new opportunities to reduce the impact of cardiovascular disease. Ganaxolone being a $\beta$-methylated form of allopregnanolone prevents the back conversion to progesterone and has been suggested therefore to be free of steroid side effects and also well tolerated (Turkmen et al., 2011). The question is how effective would such an agent be in treating human hypertension. Esler has suggested that $50 \%$ of patients with essential hypertension have the neurogenic form (Esler, 2014). This would suggest that about half of those with hypertension will be responsive to ganaxolone or allopregnanolone and particularly those "highly stress reactive" patients. However, the higher number of CRF-containing neurons in the hypothalamus of all patients that were hypertensive suggests that neurosteroid treatment may be even more widely applicable to patients with essential hypertension.

\section{CONCLUSION}

There is now extensive evidence from animal models to well documented clinical trials to support the view of a major contribution of the SNS in the etiology of essential hypertension. There is also support for the view that a larger neurogenic contribution to hypertension may be a result of the long-term impact of adverse psychosocial stressors. However, to date there are no specific therapeutics that address this mechanism, clearly indicating an area of unmet need. Neurosteroids such as allopregnanolone and the modified form, ganaxolone, may offer a completely new possibility to address the impact of chronic activation of the SNS in the development and maintenance of hypertension. These agents are safe at very high doses as shown by their use in multiple clinical trials for epilepsy and our studies suggest they are very effective is reducing neurogenic hypertension in animal models. While the mechanism is likely involving an upregulation of specific types of $\mathrm{GABA}_{\mathrm{A}} \mathrm{R}$, in areas such as the hypothalamus and 
amygdala, there is still a number of directions research can follow. The most important would be a proof of concept study of its effectiveness in essential human hypertension particularly to determine the dose levels required to be effective. With respect to the mechanism, it remains to be determined precisely which neuronal pathways are responsible and whether the upregulation of $\delta$ and $\alpha 4$ subunits is the key step and not simply an associated phenomenon. If this turns out to be the case then it may be possible to find specific transcriptional factors that regulate these receptors and possibly bypass the need to administer neurosteroids.

\section{REFERENCES}

Anderson, E. A., Sinkey, C. A., Lawton, W. J., and Mark, A. L. (1989). Elevated sympathetic nerve activity in borderline hypertensive humans - evidence from direct intraneural recordings. Hypertension 14, 177-183. doi: 10.1161/01. HYP.14.2.177

Bunker, S. J., Colquhoun, D. M., Esler, M. D., Hickie, I. B., Hunt, D., Jelinek, V. M., et al. (2003). "Stress" and coronary heart disease: psychosocial risk factors. Med. J. Aust. 178, 272-276. doi: 10.5694/j.1326-5377.2003.tb05193.x

Burchell, A. E., Chan, K., Ratcliffe, L. E., Hart, E. C., Saxena, M., Collier, D. J., et al. (2016). Controversies surrounding renal denervation: lessons learned from real-world experience in two United Kingdom centers. J. Clin. Hypertens. 18, 585-592. doi: 10.1111/jch.12789

Carretero, O. A., and Oparil, S. (2000). Essential hypertension. Part I: definition and etiology. Circulation 101, 329-335. doi: 10.1161/01.CIR.101.3.329

Carroll, D., Ring, C., Hunt, K., Ford, G., and Macintyre, S. (2003). Blood pressure reactions to stress and the prediction of future blood pressure: effects of sex, age, and socioeconomic position. Psychosom. Med. 65, 1058-1064. doi: 10.1097/01. PSY.0000097330.58739.26

Costa-Ferreira, W., Vieira, J. O., Almeida, J., Gomes-de-Souza, L., and Crestani, C. C. (2016). Involvement of type 1 angiotensin II receptor (AT1) in cardiovascular changes induced by chronic emotional stress: comparison between homotypic and heterotypic stressors. Front. Pharmacol. 7:262. doi: $10.3389 /$ fphar.2016.00262

Crestani, C. C. (2016). Emotional stress and cardiovascular complications in animal models: a review of the influence of stress type. Front. Physiol. 7:251. doi: $10.3389 /$ fphys.2016.00251

Dampney, R. A., Horiuchi, J., Killinger, S., Sheriff, M. J., Tan, P. S., and McDowall, L. M. (2005). Long-term regulation of arterial blood pressure by hypothalamic nuclei: some critical questions. Clin. Exp. Pharmacol. Physiol. 32, 419-425. doi: 10.1111/j.1440-1681.2005.04205.x

Davern, P. J., Jackson, K. L., Nguyen-Huu, T., La Greca, L., and Head, G. A. (2010a). Cardiovascular reactivity and neuronal activation to stress in Schlager genetically hypertensive mice. Neuroscience 170, 551-558. doi: 10.1016/j. neuroscience.2010.07.040

Davern, P. J., Jackson, K. L., Nguyen-Huu, T., La Greca, L., and Head, G. A. (2010b). Cardiovascular responses to aversive and non-aversive stressors in Schlager genetically hypertensive mice. Am. J. Hypertens. 23, 838-844. doi: 10.1038/ajh.2010.69

Davern, P. J., Nguyen-Huu, T., La Greca, L., and Head, G. A. (2009). Role of the sympathetic nervous system in Schlager genetically hypertensive mice. Hypertension 54, 852-859. doi: 10.1161/HYPERTENSIONAHA. 109.136069

Davies, S. J., Ghahramani, P., Jackson, P. R., Noble, T. W., Hardy, P. G., Hippisley-Cox, J., et al. (1999). Association of panic disorder and panic attacks with hypertension. Am. J. Med. 107, 310-316. doi: 10.1016/ S0002-9343(99)00237-5

DiBona, G. F., and Esler, M. (2010). Translational medicine: the antihypertensive effect of renal denervation. Am. J. Physiol. Regul. Integr. Comp. Physiol. 298, R245-R253. doi: 10.1152/ajpregu.00647.2009

DiBona, G. F., and Kopp, U. C. (1995). "Neural control of renal function role in human hypertension" in Hypertension: Pathophysiology, diagnosis and treatment. eds. J. H. Laragh and B. M. Brenner (New York: Raven).

\section{AUTHOR CONTRIBUTIONS}

All authors listed have made a substantial, direct and intellectual contribution to the work, and approved it for publication.

\section{FUNDING}

This work was supported in part by the Victorian Government's OIS Program. Investigators were supported by NHMRC Fellowships APP1091688 to KJ and APP1002186 to GH.

Esler, M. (2014). Sympathetic nervous system moves toward center stage in cardiovascular medicine: from Thomas Willis to resistant hypertension. Hypertension 63, e25-e32. doi: 10.1161/HYPERTENSIONAHA.113.02439

Esler, M., Eikelis, N., Schlaich, M., Lambert, G., Alvarenga, M., Dawood, T., et al. (2008a). Chronic mental stress is a cause of essential hypertension: presence of biological markers of stress. Clin. Exp. Pharmacol. Physiol. 35, 498-502. doi: 10.1111/j.1440-1681.2008.04904.x

Esler, M., Eikelis, N., Schlaich, M., Lambert, G., Alvarenga, M., Kaye, D., et al. (2008b). Human sympathetic nerve biology: parallel influences of stress and epigenetics in essential hypertension and panic disorder. Ann. N. Y. Acad. Sci. 1148, 338-348. doi: 10.1196/annals.1410.064

Esler, M., Jennings, G., Korner, P., Willett, I., Dudley, F., Hasking, G., et al. (1988a). Assessment of human sympathetic nervous system activity from measurements of norepinephrine turnover. Hypertension 11, 3-20. doi: 10.1161/01.HYP.11.1.3

Esler, M. D., Jennings, G. L., and Lambert, G. W. (1988b). Release of noradrenaline into the cerebrovascular circulation in patients with primary hypertension. J. Hypertens. Suppl. 6, S494-S496.

Esler, M. D., Lambert, E. A., Schlaich, M., and Navar, L. G. (2010). The dominant contributor to systemic hypertension: chronic activation of the sympathetic nervous system vs activation of the intrarenal renin-angiotensin system. J. Appl. Physiol. 109, 1996-1998. doi: 10.1152/japplphysiol.00182.2010

Esler, M., Lux, A., Jennings, G., Hastings, J., Socratous, F., and Lambert, G. (2004). Rilmenidine sympatholytic activity preserves mental stress, orthostatic sympathetic responses and adrenaline secretion. J. Hypertens. 22, 1529-1534. doi: 10.1097/01.hjh.0000125453.28861.b8

Esler, M., Straznicky, N., Eikelis, N., Masuo, K., Lambert, G., and Lambert, E. (2006). Mechanisms of sympathetic activation in obesity-related hypertension. Hypertension 48, 787-796. doi: 10.1161/01.HYP.0000242642.42177.49

Fisher, J. P., and Paton, J. F. (2012). The sympathetic nervous system and blood pressure in humans: implications for hypertension. J. Hum. Hypertens. 26, 463-475. doi: 10.1038/jhh.2011.66

Flaa, A., Eide, I. K., Kjeldsen, S. E., and Rostrup, M. (2008). Sympathoadrenal stress reactivity is a predictor of future blood pressure: an 18-year follow-up study. Hypertension 52, 336-341. doi: 10.1161/HYPERTENSIONAHA.108.111625

Flak, J. N., Jankord, R., Solomon, M. B., Krause, E. G., and Herman, J. P. (2011). Opposing effects of chronic stress and weight restriction on cardiovascular, neuroendocrine and metabolic function. Physiol. Behav. 104, 228-234. doi: 10.1016/j.physbeh.2011.03.002

Gianaros, P. J., Sheu, L. K., Matthews, K. A., Jennings, J. R., Manuck, S. B., and Hariri, A. R. (2008). Individual differences in stressor-evoked blood pressure reactivity vary with activation, volume, and functional connectivity of the amygdala. J. Neurosci. 28, 990-999. doi: 10.1523/JNEUROSCI.3606-07.2008

Goncharuk, V. D., van Heerikhuize, J., Swaab, D. F., and Buijs, R. M. (2002). Paraventricular nucleus of the human hypothalamus in primary hypertension: activation of corticotropin-releasing hormone neurons. J. Comp. Neurol. 443, 321-331. doi: 10.1002/cne.10124

Goodson, M. L., Packard, A. E. B., Buesing, D. R., Maney, M., Myers, B., Fang, Y., et al. (2017). Chronic stress and rosiglitazone increase indices of vascular stiffness in male rats. Physiol. Behav. 172, 16-23. doi: 10.1016/j.physbeh.2016.03.031

Head, G. A., and Burke, S. L. (2004). Sympathetic responses to stress and rilmenidine in $2 \mathrm{~K} 1 \mathrm{C}$ rabbits: evidence of enhanced nonvascular effector mechanism. Hypertension 43, 636-642. doi: 10.1161/01.HYP.0000116301.02975.aa 
Head, G. A., Burke, S. L., and Chan, C. K. S. (1997). Central imidazoline receptors and centrally acting anti-hypertensive agents. Clin. Exp. Hypertens. 19, 591-605.

Head, G. A., Chatzivlastou, K., Lukoshkova, E. V., Jennings, G. L., and Reid, C. M. (2010). A novel measure of the power of the morning blood pressure surge from ambulatory blood pressure recordings. Am. J. Hypertens. 23, 1074-1081. doi: 10.1038/ajh.2010.126

Head, G., Shaw, J., Dunstan, D., Owen, N., Magliano, D., Chadban, S., et al. (2019). Hypertension, white-coat hypertension and masked hypertension in Australia: findings from the Australian diabetes, obesity, and lifestyle study 3. J. Hypertens. 37, 1615-1623. doi: 10.1097/HJH.0000000000002087

Herat, L. Y., Magno, A. L., Kiuchi, M. G., Jackson, K. L., Carnagarin, R., Head, G. A., et al. (2020). The Schlager mouse as a model of altered retinal phenotype. Neural Regen. Res. 15, 512-518. doi: 10.4103/1673-5374.266069

Herman, J. P., Figueiredo, H., Mueller, N. K., Ulrich-Lai, Y., Ostrander, M. M., Choi, D. C., et al. (2003). Central mechanisms of stress integration: hierarchical circuitry controlling hypothalamo-pituitary-adrenocortical responsiveness. Front. Neuroendocrinol. 24, 151-180. doi: 10.1016/j.yfrne.2003.07.001

Imaki, T., Naruse, M., Harada, S., Chikada, N., Nakajima, K., Yoshimoto, T., et al. (1998). Stress-induced changes of gene expression in the paraventricular nucleus are enhanced in spontaneously hypertensive rats. J. Neuroendocrinol. 10, 635-643. doi: 10.1046/j.1365-2826.1998.00249.x

Jackson, K. L., Palma-Rigo, K., Nguyen-Huu, T.-P., Davern, P. J., and Head, G. A. (2014). Major contribution of the medial amygdala to hypertension in BPH/2J genetically hypertensive mice. Hypertension 63, 811-818. doi: 10.1161/ HYPERTENSIONAHA.113.02020

Jie, F., Yin, G., Yang, W., Yang, M., Gao, S., Lv, J., et al. (2018). Stress in regulation of GABA amygdala system and relevance to neuropsychiatric diseases. Front. Neurosci. 12:562. doi: 10.3389/fnins.2018.00562

Kollias, A., Ntineri, A., and Stergiou, G. S. (2014). Is white-coat hypertension a harbinger of increased risk? Hypertens. Res. 37, 791-795. doi: 10.1038/ hr.2014.35

Korner, P. (2007). Essential hypertension and its causes: Neural and non neural mechanisms. New York: Oxford University Press.

Laffin, L. J., and Bakris, G. L. (2015). Renal denervation for resistant hypertension and beyond. Adv. Chronic Kidney Dis. 22, 133-139. doi: 10.1053/j.ackd.2014.11.005

Lawler, J. E., Barker, G. F., Hubbard, J. W., and Schaub, R. G. (1980). Pathophysiological changes associated with stress-induced hypertension in the borderline hypertensive rat. Clin. Sci. 59, 307s-310s. doi: 10.1042/cs059307s

Lawler, J. E., Barker, G. F., Hubbard, J. W., and Schaub, R. G. (1981). Effects of stress on blood pressure and cardiac pathology in rats with borderline hypertension. Hypertension 3, 496-505. doi: 10.1161/01.HYP.3.4.496

LeDoux, J. (2003). The emotional brain, fear, and the amygdala. Cell. Mol. Neurobiol. 23, 727-738. doi: 10.1023/A:1025048802629

Lemaire, V., and Mormede, P. (1995). Telemetered recording of blood pressure and heart rate in different strains of rats during chronic social stress. Physiol. Behav. 58, 1181-1188. doi: 10.1016/0031-9384(95)02064-0

Lu, X. T., Liu, Y. F., Zhang, L., Yang, R. X., Liu, X. Q., Yan, F. F., et al. (2012). Unpredictable chronic mild stress promotes atherosclerosis in high cholesterolfed rabbits. Psychosom. Med. 74, 604-611. doi: 10.1097/PSY.0b013e31825d0b71

Markel, A. L. (1992). Development of a new strain of rats with inherited stressinduced arterial hypertension. Genet. Hypertens. 218, 405-407.

Markel, A. L., Redina, O. E., Gilinsky, M. A., Dymshits, G. M., Kalashnikova, E. V., Khvorostova, Y. V., et al. (2007). Neuroendocrine profiling in inherited stress-induced arterial hypertension rat strain with stress-sensitive arterial hypertension. J. Endocrinol. 195, 439-450. doi: 10.1677/JOE-07-0254

Matthews, K. A., Katholi, C. R., McCreath, H., Whooley, M. A., Williams, D. R., Zhu, S., et al. (2004). Blood pressure reactivity to psychological stress predicts hypertension in the CARDIA study. Circulation 110, 74-78. doi: 10.1161/01.CIR.0000133415.37578.E4

Nakamori, T., Morimoto, A., and Murakami, N. (1993). Effect of a central CRF antagonist on cardiovascular and thermoregulatory responses induced by stress or IL-1 beta. Am. J. Phys. 265, R834-R839. doi: 10.1152/ajpregu.1993.265.4.R834

Nalivaiko, E. (2011). Animal models of psychogenic cardiovascular disorders: what we can learn from them and what we cannot. Clin. Exp. Pharmacol. Physiol. 38, 115-125. doi: 10.1111/j.1440-1681.2010.05465.x

Pickering, T. G. (1997). The effects of environmental and lifestyle factors on blood pressure and the intermediary role of the sympathetic nervous system. J. Hum. Hypertens. 11(Suppl. 1), S9-S18.
Raftery, E. B. (1993). Carvedilol in hypertension. Cardiology 82(Suppl. 3), $40-44$.

Redina, O. E., and Markel, A. L. (2018). Stress, genes, and hypertension. Contribution of the ISIAH rat strain study. Curr. Hypertens. Rep. 20:66. doi: 10.1007/s11906-018-0870-2

Rosengren, A., Hawken, S., Ounpuu, S., Sliwa, K., Zubaid, M., Almahmeed, W. A., et al. (2004). Association of psychosocial risk factors with risk of acute myocardial infarction in 11119 cases and 13648 controls from 52 countries (the INTERHEART study): case-control study. Lancet 364, 953-962. doi: 10.1016/S0140-6736(04)17019-0

Rumantir, M. S., Vaz, M., Jennings, G. L., Collier, G., Kaye, D. M., Seals, D. R., et al. (1999). Neural mechanisms in human obesity-related hypertension. J. Hypertens. 17, 1125-1133. doi: 10.1097/00004872-199917080-00012

Sarkar, J., Wakefield, S., MacKenzie, G., Moss, S. J., and Maguire, J. (2011). Neurosteroidogenesis is required for the physiological response to stress: role of neurosteroid-sensitive GABAA receptors. J. Neurosci. 31, 18198-18210. doi: 10.1523/JNEUROSCI.2560-11.2011

Schlager, G. (1974). Selection for blood pressure levels in mice. Genetics 76, 537-549.

Schnall, P. L., Schwartz, J. E., Landsbergis, P. A., Warren, K., and Pickering, T. G. (1998). A longitudinal study of job strain and ambulatory blood pressure: results from a three-year follow-up. Psychosom. Med. 60, 697-706. doi: 10.1097/00006842-199811000-00007

Seravalle, G., and Grassi, G. (2016). Sympathetic nervous system, hypertension, obesity and metabolic syndrome. High Blood Pressure Cardiovasc. Prev. 23 , 175-179. doi: 10.1007/s40292-016-0137-4

Shimada, M., Hasegawa, T., Nishimura, C., Kan, H., Kanno, T., Nakamura, T., et al. (2009). Anti-hypertensive effect of gamma-aminobutyric acid (GABA)rich chlorella on high-normal blood pressure and borderline hypertension in placebo-controlled double blind study. Clin. Exp. Hypertens. 31, 342-354. doi: $10.1080 / 10641960902977908$

Sikora, M., Konopelski, P., Pham, K., Wyczalkowska-Tomasik, A., and Ufnal, M. (2016). Repeated restraint stress produces acute and chronic changes in hemodynamic parameters in rats. Stress 19, 621-629. doi: 10.1080/ 10253890.2016.1244667

Stevenson, E., Johns, E., Marques, F., Jackson, K., Abegaz, B., Moretti, J.-L., et al. (2017). Positive allosteric modulation of GABAA receptors attenuates high blood pressure in Schlager hypertensive mice. J. Hypertens. 35, 546-557. doi: $10.1097 / \mathrm{HJH} .0000000000001210$

Swanson, L. W., and Petrovich, G. D. (1998). What is the amygdala? Trends Neurosci. 21, 323-331. doi: 10.1016/S0166-2236(98)01265-X

Timio, M., Saronio, P., Verdura, C., Schiaroli, M., Timio, F., and Monarca, C. (2001). A link between psychosocial factors and blood pressure trend in women. Physiol. Behav. 73, 359-363. doi: 10.1016/S0031-9384(01)00489-9

Turkmen, S., Backstrom, T., Wahlstrom, G., Andreen, L., and Johansson, I. M. (2011). Tolerance to allopregnanolone with focus on the GABA-A receptor. Br. J. Pharmacol. 162, 311-327. doi: 10.1111/j.1476-5381.2010.01059.x

Weber, M. A., Mahfoud, F., Schmieder, R. E., Kandzari, D. E., Tsioufis, K. P., Townsend, R. R., et al. (2019). Renal denervation for treating hypertension: current scientific and clinical evidence. JACC Cardiovasc. Interv. 12, 1095-1105. doi: $10.1016 /$ j.jcin.2019.02.050

Whitnall, M. H. (1993). Regulation of the hypothalamic corticotropin-releasing hormone neurosecretory system. Prog. Neurobiol. 40, 573-629. doi: 10.1016/0301-0082(93)90035-Q

Yamada, Y., Miyajima, E., Tochikubo, O., Matsukawa, T., and Ishii, M. (1989). Age-related changes in muscle sympathetic nerve activity in essential hypertension. Hypertension 13, 870-877. doi: 10.1161/01.HYP.13.6.870

Conflict of Interest: The authors declare that the research was conducted in the absence of any commercial or financial relationships that could be construed as a potential conflict of interest.

Copyright $\odot 2019$ Head, Jackson and Gueguen. This is an open-access article distributed under the terms of the Creative Commons Attribution License (CC BY). The use, distribution or reproduction in other forums is permitted, provided the original author(s) and the copyright owner(s) are credited and that the original publication in this journal is cited, in accordance with accepted academic practice. No use, distribution or reproduction is permitted which does not comply with these terms. 